\title{
Phenomenal Characters of Mental States and Emerging Issues in African Philosophy of Mind
}

\author{
Fasiku Gbenga
}

Department of Philosophy

Obafemi Awolowo University, Nigeria

platoife@oauife.edu.ng

And

Oyelakin Richard Taye

Department of Philosophy

Obafemi Awolowo University, Nigeria

richyman2009@yahoo.com

Thought and Practice: A Journal of the Philosophical Association of Kenya (PAK)

New Series, Vol.3 No.1, June 2011, pp.131-143

thoughtandpractice@gmail.com

http://ajol.info/index.php/tp/index

\begin{abstract}
There is a prevalent assumption that the phenomenal character of a mental experience is an ontological property existing as part of the fabric of the world. This implies that the problem of explaining the phenomenal property of a mental experience is a metaphysical one. Contrary to this assumption, the present paper argues that phenomenal properties of mental experiences are the results of our epistemological perspectives of the world. Consequently, the paper contends that in developing issues for African Philosophy of Mind, care must, $a b$
\end{abstract}


initio, be taken to avoid the metaphysical pitfalls of considering phenomenal characters or properties of mental states to be part of the fabric of the world.

Key words. Consciousness, phenomenal property, mental experience, raw feels, qualia, Metaphysics, African Philosophy of Mind

\section{Introduction}

When I see a rose, there are light-rays emitting from the flower towards my eyes, producing an image in my retina. The visual systems are psychological properties that cause me to see the rose, and these psychological properties are explained by the cognitive sciences. Apart from these, there is the "feel" of seeing a rose - the "what it is like to' see a rose. Thus seeing a rose is one thing, and the "feel" of seeing it is another. Again, if I smile, there are physiological activities (categorized as the psychological properties) that explain the event. Moreover, there is the "feel" of smiling - the "what it is like to smile'. The mental experiences of seeing a rose and of smiling are perceptual and physiological processes, which are explainable visually and physiologically. However, there is a problem explaining what it feels like to see a rose or to smile, which are the phenomenal characters or properties of the mental experiences of seeing a rose and of smiling. These qualities have been assumed to be ontological properties existing as part of the fabric of the world. Contrary to this assumption, this paper argues that phenomenal properties of mental experiences are the results of our epistemological perspectives on the world.

In the first section, the paper explains the notion of phenomenal properties of mental states, and the hard problem of consciousness. In the second section, it argues that the problem of explaining these phenomenal properties is not a metaphysical one, and that what is considered to be the hard problem of consciousness is due to the process of human reasoning rather than an ontological process. In the third section, the paper points out that in developing issues for African Philosophy of Mind, care must, ab initio, be taken to avoid the 'hard problem of consciousness' by evading the metaphysical pitfall of considering phenomenal properties of mental states to be part of the fabric of the world.

\section{The Notion of Phenomenal Properties or Characters of Mental States}

David Chalmers distinguishes between two aspects of the mind, namely, the psychological and the phenomenal (Chalmers 1996, 30-31). In the psychological aspect, the mind is the internal mechanism or system which serves as the causal and explanatory basis of human 
actions, experiences, thoughts, beliefs, etc. In this respect, mental states are those states of the mind that are causally responsible for behaviour, experiences, thoughts, beliefs, actions, etc and through which they are explained. Moreover, in the psychological aspect, the mind is understood in terms of what it does. This, however, does not reveal the nature of the mind and its states. Rather, the cognitive science' account of the mind, which is the psychological aspect, reveals what the mind does, and not what the mind is. On the phenomenal aspect, the mind is conceived not as what causes or explains experience, but as the experience itself. This experience is qualified as conscious experience, phenomenal consciousness or qualia. Conscious experiences are the properties of our mental states, and they are instantiated as a 'felt' quality. The mind is characterized by the way it feels, and what it means for a mental state to be phenomenal is for it to feel a certain way.

There are problems associated with each aspect of the mind. With regard to the psychological aspect, one of the problems is to explicate what the internal basis (i.e. the causal processes, activities and properties) of behaviour are, and to explain how the states of this causal mechanism or process produce behaviour. For example, in an attempt to explain an experience of seeing a rose, all that is necessary is to specify perceptual properties and processes in the human being that culminate in the perceptual experience of seeing a rose. These include explaining how some photons strike the retina, and how some electrical signals are passed from the optic nerves to different areas of the central nervous system. All of these constitute the causal explanation for the mental experience of seeing a rose. This is all that psychologists, neuroscientists and neurobiologists would offer as the explanation of the mental experience of seeing a rose. This is an objective explanation verifiable through experimental apparatuses and processes.

Given a relative knowledge of neurophysiology, neuroscience and molecular biology, it is feasible to understand, explain and even predict the structures, activations and operations of the peripheral nervous system, the central nervous system, the cortex, the neurochemicals as well as the other components of the human body that culminate in the mental experience of seeing a rose. Hence, questions such as 'How does the brain process environmental stimulation like a rose?' 'How does it integrate the information received through the nerves in the human body?' can be answered in terms of specifying the causal activities and processes of the organs and properties in the human body. There could be disagreements about the nature and function of the organs and properties in the body, and about how the organs and properties play a causal role in the production of behaviour. These disagreements are 
resolvable within the cognitive and physical sciences. It is on the basis of this that problems associated with the psychological aspect of the mind are, for David Chalmers, the easy problems of consciousness. However, in Chalmers' view (Chalmers 1996), the easy problems are easy because they ask for no more than an explanation of various cognitive functions and explaining any sort of function is something that science is well suited to do. Once the relevant mechanisms are well understood, there is little or no explanatory work left to do.

Although experience is associated with a variety of functions, explaining how those functions are performed would leave important questions unanswered. We would still want to know why their performance is accompanied by experience, and why this or that kind of experience rather than another kind. So, for example, nerve stimulation and nerve damages could be the mechanisms that play the causal role of pain, leading to recoil and avoidance. Explaining these causal mechanisms could possibly be done by studying the essential nature of nerves, and finding out what happens when nerves are stimulated, or damaged. This inquiry is best suited for the cognitive sciences. This is why the problem of explaining causal mechanisms is easy.

On the phenomenal aspect of the mind, the mind is not construed as what it does, but as the "feel" that accompanies mental states. This is the subjective quality, the "what it feels like to see a rose', attached to the mental or perceptual experience of seeing a rose. This "feel" is the conscious experience, which is also known as the 'phenomenal consciousness', 'qualia', 'what it is like to be', 'raw feels', etc. The question is, there is no doubt that we can specify the mechanisms or systems, the properties and processes, etc of the perceptual experience of seeing a rose: can we also specify the mechanisms or systems, the properties and processes that explain phenomenal consciousness of the perceptual experience of seeing a rose? Why does a particular phenomenal consciousness accompany a given mental state (e.g. a particular perceptual experience) rather than a different one? This is a problem. According to Chalmers, "the problem of explaining these phenomenal qualities is just the problem of explaining consciousness. This is the really hard part of the mind-body problem" (Chalmers 1996, 4).

Some of the questions to be answered in addressing the hard problem of consciousness are:

- What are conscious experiences?

- Do conscious experiences exist?

- If conscious experiences exist, how are they produced? 
- Could conscious experiences be products of causal activities, processes or properties?

As Joseph Levine has noted, the set of questions that need answers are: "Do the features that distinguish minds from everything else in nature mark a fundamental division between the natural, or the physical, and the non-natural, or the immaterial? Are we, and the phenomena that constitute our mental lives, an integral part of the natural, physical world, or not?" (Levine 2001, 4). For instance, just as there are physiological and morphological properties, processes and activities that explain the mental experience of smiling, are the raw "feels" of the mental state of smiling - the what it is like to smile - in any way explained or explainable through the related physiological and morphological properties, processes and activities? Is 'what it feels like to smile' part of the edifice of the natural world which can be studied objectively? These questions introduce what, in the Philosophy of Mind, is called "The Hard Problem of Consciousness".

The hard problem of consciousness is centered on two fundamental issues. The first is to determine the ontological status of phenomenal consciousness or qualia, and is exemplified in questions such as the following:

- What are qualia?

- Do qualia exist?

- If qualia exist, what conditions give rise to them?

- Are such conditions open to empirical investigation?

- Are qualia predictable and explainable within the purview of an objective study provided by the physical sciences?

The second issue pertains to the need to explain why and how a particular mental experience is accompanied by some particular qualia rather than by any other. In this regard, the questions that arise include the following: 'What are these phenomena?' and 'How can each of them be known?' There is also the need to answer the question, 'What is the relationship between the two possibly separate phenomena? In other words, given the scientifically observable explanatory apparatus through which the central nervous system and its properties are explained, it is not obvious HOW and WHY, within that apparatus, we can account for the causal character of the relation between the activities, processes and properties in the 
central nervous system of a particular mental state and the phenomenal consciousness that accompanies such mental experience.

As at 2003, Robert C. Coghill et. Al. had reported that "no study to date has identified the neural correlates of an individual's subjective experience of pain and characterized them in relation to those of other individuals receiving exactly the same stimulus" (Coghill et. Al. 2003). Furthermore, in 2009, Coates et. al. were more specific in declaring that there is a mystery of conscious experiences which contemporary scientists still cannot explain:

When we see a sunset or hear a symphony our sense organs, brains and bodies are moved in ways that are well understood by the physical and biological sciences. But during such experiences we also enjoy distinctive forms of conscious awareness. Yet this undeniable fact about our conscious lives is stubbornly resistant to scientific understanding. How is it even possible for purely physical brain activity to produce conscious experience? How do the qualities that manifest themselves in experience relate to the very different properties that are referred to in scientific descriptions of the physical world? (Coates et. Al. 2009)

In other words, the hard problem of consciousness is the need to answer the question: "why and how does a given physical process generate the specific experience that it does?' Why, for example, does a physical process in the brain produce an experience of redness rather than greenness? What really defines the hard problem of consciousness is the need to account for the causal relationship between the physical properties and processes in the central nervous system and the properties of mental states called 'phenomenal consciousness'.

The hard problem of consciousness is, however, not entirely new in philosophy. It is widely accepted that consciousness poses a special explanatory problem for science. This is because the problems related to the structure and causal interactions of matter and physical entities and properties, and their implications for understanding of macroscopic and microscopic structural levels and phenomena, were successfully scientifically resolved during the past three centuries of the explosive development of the natural sciences. However, the problem of how consciousness evolves has remained scientifically unresolved (Rakovic \& Koruga 1996, 1). This same sentiment was entrenched in the writings of the $17^{\text {th }}$ century writers as exemplified by John Locke, who claimed that there is a clear distinction between the quantifiable and objectively identifiable features of reality such as bulk, figure, motion, etc., and the conscious ideas we experience of those features of reality (Locke 1979, 558-559). For Locke, the quest to establish a connection between the two is really a difficult task to 
accomplish. It is this quest that still subsists, and is redefined as the hard problem of consciousness.

Moreover, Locke's pessimism had, in the $19^{\text {th }}$ century, been taken a bit further by the biologist Thomas Huxley (1886), who asserted that the hard problem of consciousness is an enquiry into "how it is that anything so remarkable as a state of consciousness comes about as a result of irritating nervous tissues, and is just as unaccountable as the appearance of Djin when Aladdin rubbed his lamp" (Tye 1995, 15).

In the contemporary literature, the same issues identified as the Hard Problem of Consciousness have also been raised. For example, David Chalmers has written:

Consciousness is the biggest mystery. It may be the last outstanding obstacle to our quest for a scientific understanding of the universe ... We have good reason to believe that consciousness arises from physical systems such as brains, but we have little idea how it arises or why it exists at all. ... We do not just lack a detailed theory; we are entirely in the dark about how consciousness fits into the natural order (Chalmers 1996, 15).

Hence, according to Chalmers, a theory of consciousness should explain the conditions under which physical processes give rise to consciousness. The theory should explain how it arises, so that the emergence of consciousness seems intelligible rather than magical. In the end, Chalmers says "we would like the theory to enable us to see consciousness as an integral part of the natural world. Currently, it may be hard to see what such a theory would be like. But, without such a theory we could not be said to fully understand consciousness" (Chalmers 1996, 5).

McGinn (1997) also expressed the same worry when he asked how technicolor phenomenology can arise from 'grey soggy matter'. He put the question more succinctly as follows:

How could the aggregation of millions of individually insentient neuron generate subjective awareness? We know that brains are the de facto causal basis of consciousness, but we have, it seems, no understanding whatever of how (and why) that can be so. It strikes us as miraculous, eerie, even faintly comic. Somehow, we feel the water of the physical brain is turned into the wine of consciousness but we draw a total blank on the nature of the conversion (McGinn 1997, 529).

In a more explicit manner, Michael Tye introduces the hard problem of consciousness by asserting that we are all material beings who have experiences and feelings. According to him, 
"we perceive things with our senses, and in so doing we undergo perceptual experiences; we have bodily sensations; we feel a variety of emotions and moods. These things are subjective, or, at any rate, they have a subjective side. How can they just be a matter of matter?'(Tye 2009, 11). Moreover, the pessimism about a successful physicalist or materialist explanation of consciousness is forcefully expressed in Jerry Fodor's view. For him, "nobody has the slightest idea how anything material could be conscious. Nobody even knows what it would be like to have the slightest idea about how anything material could be conscious" (Fodor 1992, 5). Thomas Nagel (1991) was inclined to believe that the problem has no solution. According to him, "the subjective features of conscious mental processes - as opposed to their physical causes and effects - cannot be captured by the purified form of thought suitable for dealing with the physical world that underlies appearances" (Nagel 1991, 372).

\section{The Hard Problem of Consciousness: A Phenomenal of the Noumenal}

In my view, the assumption that a phenomenal character accompanies a mental state is based on a belief about what exists in the world, and such a belief needs further justification. Consequently, the need to explain phenomenal properties of experience is an epistemological problem. The question of 'what' causes what is metaphysical and the question of how it is caused is epistemological; the former is not problematic, it is a matter of fact, but the latter is a problem. In other words, what is described as the hard problem of consciousness (i.e., questions about the relationship between the phenomenal character of a mental state and the brain states/properties) is purely an epistemological, and not a metaphysical, problem.

There are two conceptions of metaphysics. The first is that metaphysics is an enquiry into the nature of reality. In this sense, metaphysicians examine reality as it is and derive facts about its structure, scope and order. The second conception is that metaphysics is a self-reflective exercise that seeks to gain an understanding of how we (human beings) represent facts about reality to ourselves (Bunnin \& Tsui-James 1996, 64). In this latter sense, the concern of metaphysicians is about how our conceptual and semantic schemes structure our thoughts about reality. In other words, the concern of metaphysics is not reality as it is, but rather the relationship between our conceptual and semantic schemes on the one hand, and reality on the other. The first conception of metaphysics fits into what is identified as real metaphysics (in which metaphysics is an attempt to describe the actual, fundamental structure of the world). The second exemplifies what is identified as descriptive metaphysics (in which 
metaphysics is merely a depiction of 'the actual structure of our thought about the world') (Tienson 1989, 63).

The two conceptions of metaphysics are reminiscent of the Kantian distinction between noumena (things in themselves) and phenomena (things as perceived by conscious beings). What links the two conceptions of metaphysics is that reality as it is exists unmediated, and metaphysicians construe it as facts either derived through or mediated by our conceptual schemes. Nevertheless, it is important to note that Kant's conception of things in themselves as noumena, contrasted with empirical objects as phenomena, is controversial. ${ }^{1}$ In a sense, it is correct to argue that the latter is also a part of the former. This is because the derived facts about reality and the reality represented by conceptual schemes both exist in the 'underived' and 'unrepresented' reality (i.e. reality as it is). It is in this sense that Tienson $(1989,63)$ was correct in affirming that "there is a world, and our thought about it is but part of that world. Any complete philosophical position must tell a story about the structure of our thought, a story about the wider world of which that thought is a part, and a story about how the two are related." This implies that there is the way the world is, independent of any derived facts, conceptual representations, thoughts etc, and the emotional approval or otherwise of derived facts and conceptual representations (Ward 2011, 131-141).

Strictly speaking, it follows from Ward's assertion above that a story, which is an account of our conceptual scheme about the world, is different from the world as it is. However, following Tienson's argument, the distinction between the way the world is (reality) and our conceptual representations of it is insufficient. This is because Ward's derived facts, conceptual representations and thoughts, etc are properties of the world to the extent that Ward himself is a part of the world. Nevertheless, notwithstanding the fact that Ward's conceptual scheme is one of the properties of the world, it is, at the same time, used to describe the world. This description could either be true or false.

From the foregoing observations, we can infer that the claim that mental states are accompanied by some qualitative properties is itself part of our conceptual scheme about the world as it is. According to Lynn (1985, 95-108), our beliefs and assertions are subject to error, which implies that they require some kind of justification. The possibility that things could have been different from what they are, or that the mental states may have been

\footnotetext{
${ }^{1}$ For a comprehensive interpretation and defense of the distinction, see Adams (1997, 801-825).
} 
accompanied by properties other than phenomenal consciousness or raw "feels", suggests that the issue of whether or not mental states are accompanied by qualitative properties in objective reality is itself debatable.

Besides, the foregoing reflections suggest that claims about the nature of qualitative properties (also known as phenomenal characters or properties of a mental experience, phenomenal consciousness, qualia, raw "feels" or conscious experience etc) are mere epistemological claims, and as such, subject to systematic error. More importantly, just as the hard problem of consciousness is correctly understood to be an epistemological problem of how and why qualitative properties accompany mental experiences, the foregoing reflections show that it should be correct to assert that the claim that mental experiences are accompanied by qualitative properties is also an epistemological claim rather than an objective fact.

\section{Phenomenal Properties and the Emerging Issues in African Philosophy of Mind}

Now that the debate on the existence of African philosophy has subsided, the stage is set to engage some emerging issues that form the fulcrum of discourse in all aspects of African Philosophy (Makinde 2010, 23-66). Issues that relate to the mind-body problem, which have hitherto been discussed under metaphysics (Abimbola 1971; Makinde 1983, 1984, 1985; Gbadegesin 1984; Hallen 2009, etc.) should, in our opinion, be properly categorized as issues in African Philosophy of Mind. For example, some of the philosophical discourses on Yoruba concepts such as ori ("inner head", understood as a bearer of destiny), ese ("leg"), emi ("soul" or "spirit") and ara ("physical human body"), in relation to theories such as dualism, monism and physicalism that featured in the works of Abimbola, Makinde, Gbadegesin, Hallen, etc, if engaged differently, point to some emerging issues that correspond to the kinds of problems that characterize contemporary Western debates in the Philosophy of Mind.

Furthermore, the basis of Chief Obafemi Awolowo's African Socialism is laden with assumptions about the nature of mind, its properties or character, and its relationship to other entities and properties in the world (Awolowo 1968). Nevertheless, discussions of Awolowo's ideas were undertaken on the assumption that questions about the mind, the body, their properties and relationships either do not arise, or have been settled (Makinde 1988, 5985; Nwanwene 1970, 196; Omoboriowo 1982, 3-25; Ogundimu 1978). In the same vein, emerging issues from discourses on mental health in indigenous African medicine indicate 
that there is a need to critically examine and properly conceptualize the relationship between mental states and their phenomenal characters or properties on the one hand, and brain states and behaviour on the other (Makinde 2010, 372-398). More importantly, Africans' understanding of, and approach to, cases of mental illnesses would be more positive if they were not entangled with the assumption that phenomenal properties of mental states are parts of physical properties of the mind. This would assist indigenous African medical experts to improve the quality of their health care, thereby providing holistic healing of mental illnesses.

Our assumption is that some of the issues that would emerge for discourses and debates in African Philosophy of Mind are the African conceptions of the mind, mental states, phenomenal properties or characters, the relationship between mental states and their phenomenal characters, the relationship between the mental states and brain states, etc. However, in the event that the above prognosis on African Philosophy of Mind is, in the nearest future, taken seriously, it would be important to note that African philosophers should be mindful of the assumptions that created what, in the contemporary discourse in philosophy of mind in the western world, has been described as a hard problem. If this warning is not heeded in engaging the emerging issues in African Philosophy of Mind, the same scenario of hard problems might inhibit the proper take-off of a specialized area of philosophical discourse. However, it could be argued that hard problems need not be avoided in philosophy, and that obviously, African philosophers would take diverse positions on the problems. Indeed, if it is correct that Africans live in diverse metaphysical universes (Mbiti 1970), there would hardly be a consensus among them on the nature of phenomenal characters of mental states. It would, nevertheless, be philosophically beneficial to the take off of discourses in the African Philosophy of Mind to accept that phenomenal characters do not exist as part of the fabric of the world, thereby avoiding discussions on the hard problem of consciousness in order to address more pertinent issues.

\section{Conclusion}

Current Western discourse on the Philosophy of Mind centres on what is called the hard problem of consciousness. However, in this paper, we have argued that discussions on the hard problem of consciousness should be preceded by a justification of the claim that in reality, a mental state is accompanied by some qualitative properties. We have attempted to show that rather than being a matter of fact, the claim that a mental state has some raw "feels" attached to it is a belief, an expression of a conceptual scheme, or a story about reality. 
As such, we have contended that the hard problem of consciousness is an epistemological one. We have gone on to argue that in emerging issues that would form the center of discourses and debates in African Philosophy of Mind, the position that phenomenal properties of mental states are ontological properties in the world be avoided, so as not to, ab initio, be saddled with the need to explain and justify the assertion that phenomenal characters exist as part of the fabric of the world, which would create an unnecessary hard problem.

\section{References}

Abimbola, W. 1971. "The Yoruba Concept of Human Personality". La Notion de Personne en Afrique Noire. Colloques Internationaux de Centre National de la Recherche Scientifique, No.544, pp.73-89.

Awolowo, Obafemi. 1968. The People's Republic. Ibadan: Oxford University Press.

Bunnin, Nicholas and E.P. Tsui-james. 1996. Blackwell Companion to Metaphysics. Oxford: Blackwell Publishers Ltd.

Chalmers, David J. 1996. The Conscious Mind: In Search of a Fundamental Theory. Oxford: Oxford University Press.

Coates, Paul and Sam Coleman. 2009. "Researchers Explore What Contemporary Science Cannot Explain". Science Daily. http://www.sciencedaily.com/releases/2009/01/090123075632.htm

Coghill, Robert C., John G. McHaffie and Ye-Fen Yen. 2003. "Neural Correlates of Interindividual Differences, in The Subjective Experience of Pain". Proceedings of the National Academy of Sciences (PNAS), Vol.100 No.14, pp.8538-8542.

Fodor, Jerry A. 1992. “Can There be a Science of Mind?" Times Literary Supplement, No.4657, pp.5-7.

Gbadegesin, E.O. 1984. "destiny, Personality and the Ultimate Reality of Human Experience: A Yoruba Perspective". Ultimate Reality and Meaning, Vol.10 No.1, pp.173-188.

Levine, Joseph. 2001. Purple Haze: The Puzzle of Consciousness. Oxford: Oxford University Press.

Locke, John. 1979. An Essay Concerning Human Understanding, Chap IV, iii, 28. Oxford: Clarendon Press.

Lynn, Stephens G. 1985. "Noumenal Qualia: C.S. Peirce on Our Epistemic Access to Feelings". Transactions of the Charles S. Peirce Society, Vol.21 No.1, pp.95-108.

Makinde, M. Akin. 1983. "Immortality of the Soul and the Yoruba Theory of Seven Heavens (Orun Meje)". Journal of Cultures and Ideas, Vol.1 No.1, pp.31-59.

--. 1984. "An African Concept of Human Personality: The Yoruba Example". Ultimate Reality and Meaning (Inter-disciplinary Studies in the Philosophy of Understanding), Vol.7 No.3, pp.189-200. 
--. 1985. "A Philosophical Analysis of the Yoruba Concepts of Ori and Human Destiny". International Studies in Philosophy, Vol.17 No.1, pp.54-69.

--. 1988. African Philosophy, Culture, and Traditional Medicine. Ohio: Ohio University Center for International Studies.

--. 2002. Awo as a Philosopher. Ile-Ife: Obafemi Awolowo University Press.

--. 2010. African Philosophy: The Demise of A Controversy. Ile-Ife: Obafemi Awolowo University Press.

Mbiti, John S. 1970. African Religions and Philosophy. New York: Double Day \& Company Inc.

McGinn, Colin. 1997. "Can We Solve the Mind-Body Problem?" Block, Ned, Owen Flanagan and Guven Guzeldere eds. The Nature of Consciousness. Cambridge, Mass.: MIT Press, pp.529-542.

Merrihew, Adams Robert. 1997. "Things in Themselves”. Philosophy and Phenomenological Research, Vol.57 No.4, pp.801-825.

Nagel, Thomas. 1991. "The Problem of Consciousness". Dennett, David ed. Consciousness Explained. London: Allen Lane.

Nwanwene, Omoregbe. 1970. “Awolowo's Political Philosophy”. Quarterly Journal of Administration, Vol.4 No.2.

--. 1971. “Awolowo's Strategy and Tactics of the People's Republic of Nigeria - A Review Article”. Quarterly Journal of Administration, Vol.5 No.2.

Ogundimu, B.A. 1978. "Personality Variable in Political Leadership and Decision Making: An Analysis of Obafemi Awolowo's Operational Codes". Quarterly Journal of Administration, Vol.XII No.3.

Omoboriowo, Akin. 1982. Awoism: A Select Theme of the Complex Ideology of Chief Obafemi Awolowo. Ibadan: Evans Brothers.

Rakovic, Dejan and Djuro Koruga. 1996. Consciousness: Scientific Challenge of $21^{\text {st }}$ Century. Belgrade: European Centre for Peace and Development (ECPD) of the United Nations University for Peace.

Searle, John. 1994. "The Problem of Consciousness". Revonsuo, Antti and Matti Kamppinen eds. Consciousness in Philosophy and Cognitive Neuroscience. New Jersey: Lawrence Erlbaum Associates Inc., pp.93-104.

Tienson, John L. 1989. “A Conception of Metaphysics”. American Philosophical Quarterly, Vol.26 No.1, pp.63-71.

Tye, Michael. 1995. Ten Problems of Consciousness. Cambridge, MA: The MIT Press.

--. 2009. Consciousness Revisited: Materialism without Phenomenal Concepts. Massachusetts: The MIT Press.

Ward, E. Jones. 2011. "Being Moved by a Way the World is Not”. Synthese, 178, pp.131-141. 